\title{
Aportaciones de la investigación cualitativa sobre videojuegos
}

\author{
Patricia Núñez Gómez \\ Profesora Titular Comunicación Audiovisual y Publicidad. Universidad Complutense de Madrid \\ Aurora Rodríguez del Barrio y Juvenal García Álvarez \\ Investigadores del Gabinete de Estudios en Acciones Comunicativas
}

\section{Resumen:}

El objetivo de la investigación es profundizar sobre la percepción de los niños hacia los videojuegos, su manera de estar ante ellos y el lugar que ocupan en sus vidas. Los autores utilizan mini grupos de discusión con niños y niñas entre 7 y 9 años y entre 10 y 12 separados por género combinando hábitat y clase sociocultural.

Los hábitos de los hogares, de estudio, el tiempo que pasan con sus padres y otros niños y el hábitat determina decisivamente la cantidad de tiempo que dedican a jugar reforzando anteriores estudios del mismo equipo sobre la idea de que los videojuegos y otros contenidos audiovisuales no son malos por sí mismos sino dependiendo de múltiples factores. Diferencias entre edades y género son también tratadas en este artículo.

Palabras clave:

Niños, videojuegos, ocio audiovisual, investigación cualitativa

Abstract:

The objective of this investigation is to delve further into children's perception of video games, how they behave with them and the place they occupy in their lives. The authors have used mini- 
discussion groups with boys and girls aged 7 to 9 and 10 to 12, separated by gender, combining habitat and socio-cultural class.

Habits at home and when studying, time spent with parents and other children, and their habitat, have a decisive influence on the amount of time spent playing video games. These findings support earlier studies conducted by the same team regarding the idea that video games and other audiovisual contents are not harmful in themselves, but depend on many different factors. Differences between ages and genders are also discussed in the article.

Key words:

Childrens, video games, audio-visual free time, qualitative research

\section{Introducción}

En 1990, en el Gabinete de Estudios en Acciones Comunicativas comenzamos un estudio de carácter cualitativo acerca del consumo audiovisual entre los niños y las niñas de entre 7 y 12 años.

La metodología que se utilizó: mini-grupos de discusión con niños y niñas de entre 7 y 9 años y entre 10 y 12 años, separados por género, combinando hábitat y clase socio-cultural. Los minigrupos son el instrumento más adecuado para la recogida de la producción discursiva a estas edades, así como la separación por géneros.

En efecto, hasta superada la edad adolescente, la comunicación entre géneros es escasa, cuando no conflictiva, dañando las dinámicas de la investigación o bloqueándolas.

Asimismo, los niños y las niñas aún no están preparados para reuniones con grupos grandes en las que todos puedan participar, ya que son más sensibles a los liderazgos, a los frenos para la intervención y menos permeables a la disciplina de intercambio del turno de palabra.

En 2006-7 hemos vuelto al mismo diseño aunque, a diferencia de la primera etapa, nos hemos centrado específicamente en el campo de los vídeo-juegos para los diversos soportes, sin abarcar el mundo general del consumo audiovisual en el planteamiento de la investigación. No 
obstante, las referencias a dicho consumo, televisivo o de otros tipos, ha aparecido espontáneamente, por lo que el contexto de la relación entre los niños y niñas y el uso y consumo de videojuegos ha quedado suficientemente contextualizado.

Por otra parte, hay que notar que la recogida de información terminó cuando empezaba a circular en el mercado la consola Wii de Nintendo. Dicha consola ha supuesto una revolución, no ya en el consumo y uso de los videojuegos entre la infancia sino, lo que es más importante para el resultado de las investigaciones, en la comprensión del mundo de los videojuegos para los adultos de todas las edades. Tanto que la nueva consola ha entrado en centros de rehabilitación o de acogida para personas ancianas o en hospitales y centros de rehabilitación generales.

Además, la Wii es una consola que, en su misma construcción física, tiene la posibilidad de hacer relacional y social lo que los adultos percibían como aislante y alienado (ver cap. 3). Es decir, que la opción de relacionarse con otros niños y niñas no la tiene el jugador dependiendo del juego que escoja, sino desde el mismo soporte que la nueva consola ofrece.

Esperamos observar esta revolución, en relación con ambos aspectos -y los que puedan surgir de su extensión en el mercado- en sucesivas investigaciones.

Antes de describir los principales resultados de esta línea de indagación, queremos destacar algunas cuestiones relacionadas con el mismo.

En primer lugar, la sorpresa que ha provocado en el equipo lo poco que han cambiado los resultados en cuanto a la percepción de los niños y las niñas de los videojuegos, su manera de estar ante ellos y el lugar que ocupan en sus vidas, 17 años después de nuestra primera aproximación al tema.

Las diferencias de género, los hábitos de compra y uso e incluso el rol de los padres se han mantenido sin grandes variaciones a lo largo de estos años. Y esto a pesar del enorme cambio tecnológico que se ha vivido desde entonces.

En segundo lugar, recordar que la aproximación cualitativa no tenía ni tiene en cuenta el prejuicio cultural sobre los videojuegos como amenaza. Ni todo lo contrario. Ni integrados ni apocalípticos. 
En este sentido, no parte de hipótesis previas; aunque parece claro que es un discurso generalizado el que estigmatiza a los medios audiovisuales desde una concepción pasiva y "hueca” del niño, como si los medios audiovisuales fueran un relleno incontrolado que colmará el cerebro vacío de nuestra infancia.

De nuestro estudio, como sucedió en otros países, emergieron tres aspectos importantes que quedan recogidos en el presente artículo:

\section{El concepto de "apropiación" frente al concepto de "efectos";}

\section{El concepto de "competencia mediática" frente a la imagen de la "recepción pasiva"}

y el papel de los adultos respecto de los medios audiovisuales y, en este caso, de los videojuegos.

En el caso de la apropiación, los resultados de la investigación nos llevaron a considerar que los niños y las niñas no son recipientes vacíos en espera de contenidos externos: son personas que elaboran lo que ven y son capaces de problematizarlo en relación con sus contextos de vida. Todo lo que les llega es evaluado, transformado e intercambiado en su mundo.

Tanto más cuanto que niños y niñas, educados y acostumbrados a construir, de-construir (strictu sensu) y re-construir los relatos audiovisuales, están en unas condiciones de lectura, decodificación e intercambio con los pares de los mensajes mediáticos diferentes, por decirlo de manera neutra, a las de las generaciones anteriores. Es muy difícil encontrar en los discursos de niños y niñas una repetición mecánica o una reproducción acrítica de lo que ven, de lo que juegan, de lo que intercambian con sus pares.

Es evidente que los medios de socialización (y no sólo los audiovisuales) pueden mostrar a los niños y a las niñas contra-valores que los adultos no estimamos aceptables.

De ahí que se hiciera visible que los niños y niñas que mejor se manejaban con la diferenciación entre realidad y ficción y con la distinción entre valor y contravalor fueran aquellos y aquellas que son acompañados en la lectura de los contenidos por los adultos (padres y madres, educadores y educadoras). 
Está claro que las tres dimensiones, (la apropiación, la competencia mediática y el papel de los adultos) fueron muy discutidas en los primeros años 90, en los que la posición de prevención contra los soportes y mensajes audiovisuales y contra los videojuegos estaba muy extendida, alimentada por algunos casos que suscitaron alarma socio-mediática. Las posiciones más conductivistas y las fenomenológicas condenaban los soportes mediáticos y los "contenidos" de los mismos como la mega-causa de "efectos dañinos" entre los niños y las niñas, advirtiendo que estos modelos podían dar lugar a generaciones ultra-violentas, acríticas e incapaces de desarrollar una diferenciación entre la realidad, la ficción, lo "bueno" y lo "malo".

Desde una perspectiva de la construcción cultural de los medios, soportes y contenidos audiovisuales, tal prejuicio tenía que tomarse como tal. Desde el punto de vista del análisis semiológico y cultural debía ponerse en cuestión la indefensión de los niños, la uniformidad de los hábitos y analizarse cómo los contenidos y los hábitos eran leídos por niños y niñas, y cómo estas lecturas tenían que ser, por fuerza, más problemáticas que una simple coacción a seres cognitivamente indefensos. Por decirlo en una palabra: nuestras investigaciones siempre han visto que los niños y las niñas no son tan manipulables y teledirigibles como el discurso general los presenta. Al menos no en relación con el consumo audiovisual.

En las aproximaciones cualitativas se conocen los efectos físicos dañinos de la sobre-exposición a actividades audiovisuales, tal como se recogen en las advertencias de los videojuegos y las consolas, pero sabemos también que los niños y las niñas conocen y temen mayoritariamente estos riesgos y que el debate sobre este problema no debe alimentar el prejuicio acerca de los juegos ni del soporte.

En el presente artículo, por tanto, nos ceñiremos a los resultados de nuestras investigaciones, haciendo referencia, en primer lugar al papel que desempeñan los vídeo-juegos en el tiempo libre de niños y niñas. En segundo lugar, veremos la importancia del género en la percepción, valoración y hábitos de los niños y las niñas en relación con los videojuegos. Después, examinaremos la distinción entre la realidad y la ficción en relación con las formas de apropiación de los relatos y modelos que los videojuegos proponen a niños y niñas. En cuarto lugar, vere- 
mos el papel que los adultos y, en especial, los padres y las madres, desempeñan, de acuerdo con el discurso de niños y niñas, en los hábitos y valoraciones en torno a los videojuegos. Finalmente, repasaremos las fuentes de información que niños y niñas manejan a la hora de escoger los videojuegos y cómo estos son también fuentes de información y, en última instancia, herramientas educativas a menudo minusvaloradas y muy poderosas.

\section{El Tiempo Libre}

En nuestro primer estudio, los investigadores del equipo nos encontramos perplejos ante un hecho: los niños y las niñas, cuando les preguntábamos por su tiempo libre muy raramente aludían a la televisión, o a los videojuegos.

En el caso de los videojuegos, pensábamos que la penetración de los mismos en los hogares como soporte o como objeto de consumo aún no estaba lo suficientemente extendida. Pero para el caso de la televisión no teníamos explicación.

Afortunadamente, por el mismo carácter progresivo de la metodología cualitativa, pudimos preguntar directamente a los niños y las niñas por qué no mencionaban la televisión cuando les preguntábamos por sus hábitos. La respuesta, desde el punto de vista semiológico era casi sonrojante para nosotros, pero clave para el análisis:

“Tú nos preguntas qué hacemos en nuestro tiempo libre, y te contamos lo que hacemos. Ver la televisión es no hacer nada. La vemos cuando no tenemos nada que hacer".

Para los niños y las niñas, el "tiempo libre" no se dedica, normalmente, a consumir productos audiovisuales: la televisión, el ordenador y los videojuegos son el último refugio contra el aburrimiento. Lo que les gusta es jugar con otros niños y niñas.

Por otra parte, hay que hacer notar una dimensión que diferencia los videojuegos de consola y, frecuentemente, de ordenador (no siempre los portátiles, como PSP, Game Boy, etc...) de otros soportes audiovisuales: es la posibilidad de que jueguen dos o más jugadores. En este contexto, hay que notar que el videojuego tendría dos caras: cuando se juega solo y cuando se juega con otros niños o niñas. 
Así, cuando la consola es motivo de reunión y de juego colectivo entra dentro de sus actividades de tiempo libre en el buen sentido (para ellos y ellas) de la palabra. Comparten, compiten, discuten, se ríen... en conjunto, en compañía de pares. En este sentido, los videojuegos no se diferencian de ninguna otra actividad lúdica de niños y niñas. La estructura y función socio-antropológicas de unas y otras actividades son idénticas.

Muy diferente es el "peligro" -que los niños y las niñas en conjunto detectan como tal, y esto es esencial tenerlo en cuenta—que representa el juego continuado en solitario.

En efecto, la práctica totalidad de participantes en la investigación, niños y niñas, o bien conocen a otros chicos que "se han enganchado" o que "son unos frikis", o bien ellos o ellas han pasado "épocas” en las que se han visto demasiado absorbidos por la consola.

Habitualmente, hablan de un problema menos grave cuando tratan de "pasarse una pantalla", es decir, cuando tratan de superar un estadio especialmente difícil del juego. En este caso, consideran que el "problema”, el "enganche” era sólo temporal. Una vez resuelto ese problema suelen tomarse el juego con tranquilidad.

Pero otros niños continúan "enganchados" una vez que han superado esas etapas o lo están con diferentes juegos. Suelen medir ese "enganche” cuando el "enganchado" (suele ser un varón) renuncia a otras actividades de juego, "desaparece” para jugar.

Es entonces cuando niños y niñas reconocen y estigmatizan a otros niños o niñas adictos. Incluso diagnostican problemas: creen que los niños "enganchados" tienen problemas psicológicos o "algo pasa en sus casas". Son gente rara.

Los hábitos de los hogares, de estudio, el tiempo que pasan con sus padres y otros niños y el hábitat determinan decisivamente la cantidad de tiempo que dedican a jugar juegos virtuales.

Así, normalmente los niños con "más calle” dedican menos tiempo a los videojuegos individuales, aunque mantienen la frecuencia de reunión con los pares porque frecuentemente forman parte de grupos, de "pandillas", que rotan actividades lúdicas e integran en ellas los videojuegos jugados en colectivo. 
Los niños y niñas que viven en el centro de las ciudades o en lugares aislados tienen pocas oportunidades, no ya de hacer colectivos, sino simplemente de salir o estar con otros.

Con la suficiente frecuencia, los niños y niñas participantes observan que a menudo el estilo de vida de los padres también es determinante: consideran que si sus padres están fuera muchas horas, es más fácil que el videojuego, la televisión o el ordenador llenen un tiempo en el que están solos.

De hecho, como veremos más adelante y como ya mencionamos, el que los padres conozcan los juegos, tengan cierta habilidad con ellos y se integren de vez en cuando en el grupo de jugadores no sólo les hace gracia, sino que les ayuda a controlar mejor los tiempos y los significados de los juegos. En el apartado correspondiente, veremos que el videojuego se convierte en escenario de relación entre padres e hijos. Como ventaja complementaria, llevará a esos padres y madres a tener mucha más autoridad ante ellos a la hora de "dosificar" el acceso al soporte y a los contenidos.

De todo ello se desprende que, como ocurre con la televisión o el ordenador -en su aspecto no lúdico—, los niños sólo recurren a "no hacer nada" o a "jugar en solitario" cuando no tienen otros niños o niñas con los que jugar. Y eso depende, por tanto, del espacio del que puedan disponer, del entorno familiar y de la presencia de los padres.

Por último, no podemos dejar de mencionar que, preguntados los participantes por los videojuegos y los hábitos asociados, los programas de live chat (messenger y otros) son asimilados a los juegos de ordenador, sobre todo por parte de las niñas: veremos el porqué en el siguiente apartado.

\section{El Género}

El género es un eje decisivo de diferenciación en el consumo de videojuegos, y de todos los productos y actividades audiovisuales. 
La diferencia se detecta en todos los relatos discursivos de niños y niñas cuando se refieren, tanto a los hábitos de jugar, como al tipo de juego y al conocimiento y el intercambio de información sobre los juegos.

Desde luego, hay niños y niñas que trascienden las diferencias, pero los casos no son nada frecuentes.

En nuestros primeros estudios descubrimos una constante de percepción y apropiación de los relatos -no solo los audiovisuales, claro, pero los niños suelen acercarse fundamentalmente a estos- muy diferente en función del género.

a) Los niños reconstruyen lo audiovisual de manera fragmentaria. Cuando se les pide que reconstruyan, que re-cuenten lo que han visto en la televisión o el cine, en qué consiste un juego o cómo es el cuento que han leído, los niños fijan escenas.

En términos más técnicos de análisis del discurso, los niños / cortan/ y separan algunos elementos significativos: escenas aisladas, expresiones del héroe en un momento específico del relato, acciones concretas que han llamado su atención... elementos /sueltos/, aislados de la cadena sintagmática a través de la cual expresan códigos simplificados de manera paradigmática: una película es buena si una frase del protagonista les ha hecho reír; un videojuego es bueno si hay un personaje o un elemento sorpresivo; etc...

En general, es una manera de recontar, de relatar de los niños que suelen aplicar a todos los aspectos de su vida. También cuando se les pregunta de manera cotidiana responden en clave de lo que podríamos llamar / código significativo/, de un detalle específico que para ellos es la condensación del significado de lo que se les pide relatar. Y esto dura más allá de la preadolescencia, tal y como hemos visto en otros estudios del grupo.

b) Las niñas son muy diferentes: se apropian de los relatos y los re-cuentan de manera relacional. Cuando tienen menos edad, tienden a buscar parentescos -padres, madres, 
hermanas y hermanos...-; cuando van creciendo, buscan amistades, enemistades, encuentros y desencuentros entre los protagonistas...

Casi podríamos resumir esta dimensión diciendo que los niños se fijan en /cosas/ y funciones (atributos, objetos, acciones que codifican a los personajes) y las niñas en /personas/ y en sus redes de relación.

Esto hace que las niñas sean también algo más / moralistas/ en sus juicios y recuentos. Sobre todo porque no sólo relacionan tramas entre los personajes, sino que llevan lo relacional hacia el meta-relato: es decir, ponen en conexión y comparan las relaciones entre los personajes de los relatos y sus valoraciones con los roles morales y los modos y modelos que sus padres o profesores les muestran.

Las consecuencias de la diferencia entre niños y niñas tienen que ver con todas las dimensiones de la percepción, la valoración y los hábitos asociados a los videojuegos:

El género y las preferencias de uso y consumo de videojuegos:

Este eje diferenciador es quizá el que puede explicar de manera más sencilla el hecho de que los juegos de acción sean preferidos por los niños, mientras que los arcades de ingenio o los participativos / concursos lo sean por las niñas.

También hace plausible el hecho de que las niñas den mucha más importancia a los videojuegos que solamente se juegan en compañía, que tienen menor valor competitivo y son más cercanos a actividades "reales" o cotidianas: karaoke, los Simms, juegos de estrategia, etc.

Pero además, explica también una dimensión nueva: cuando a las niñas se les pregunta por los videojuegos, incluyen los programas de live chat, como indicábamos arriba. Es evidente que la sinonimización entre el soporte y el contenido lo hacen las niñas porque el objeto y los usos de dichos programas son esencialmente relacionales.

Y, mientras, los chicos se comunican con ellos usándolos precisamente como medio de comunicación; las chicas lo incorporan con pleno derecho a su descripción de su 
escenario lúdico. Para las niñas, en puridad, jugar es relacionarse y, en cierta medida, viceversa.

El género y los hábitos y modos de juego:

Los niños "entran" en los mundos asumiendo personajes. Las niñas juegan desde posiciones más externas al juego: les gusta mandar sobre las interacciones de los personajes.

Los niños trascienden el soporte y se informan sobre los juegos. Forman parte de sus conversaciones cotidianas y de su /saber/ frente a los pares. Las niñas hablan de sí mismas y de sus mundos. Se ríen de la relación de los niños con los juegos.

Para los niños el juego compartido con otros es una manera de relación dentro del mundo virtual. Para las niñas, el juego con otras es una profundización de sus relaciones en el mundo real.

Los niños aceptan la ficción como un lugar en el que vivir de acuerdo con las reglas del mundo virtual. Las niñas aceptan la ficción como proyección de sus intereses, hábitos y relaciones.

El género y la percepción del contenido de los juegos:

Niños y niñas distinguen entre realidad y ficción. Sólo que los niños /devienen/ y las niñas /juegan a ser/.

Los niños se transforman y entran en el juego personalizando el rol protagonista, adaptándose al escenario que el juego propone.

Las niñas se disfrazan, es decir, se revisten de rol, se acomodan al escenario, pero mantienen su núcleo identitario: son más capaces de transformar y adaptar lo que el videojuego propone a su propio criterio, a sus mundos.

Desde luego, ni el alcance ni la intención de este artículo consisten en analizar las causas profundas de estas diferencias ni de sus mecanismos: puede que tengan que ver con la transmisión social y cultural de los roles que los adultos practicamos. 
a) Yo Soy, Tú Eres: la Ficción y la Realidad.

Ya hemos explicado que, en contra del prejuicio, los niños y las niñas distinguen normalmente la realidad de la ficción. Pero el mayor atractivo de un videojuego (si está bien hecho) es precisamente el de traspasar esa frontera, o borrarla. El videojuego ofrece la posibilidad de "estar" en él, aunque hayamos visto que las maneras de estar sean diferentes para niños y niñas.

El "estar en otro mundo" es "realizar" las imaginaciones. Es acceder a los mundos de fantasía que se representan en las aventuras, en los escenarios de los juegos de rol o de /vidas virtuales/, en las competiciones deportivas, ... Los niños y las niñas no dejan de usar la imaginación: digamos que el videojuego les permite poner los efectos especiales, el atrezzo, el vestuario...

El juego siempre ha consistido en "ser", en "hacerse" otro u otra. En protagonizar, modificar, vivir y morir en la ficción como cuando los referentes eran leídos o vistos en una pantalla de cine. Los mundos virtuales hacen más fácil y espectacular lo que siempre han hecho los niños y las niñas: vivir en otro mundo, asumir personajes, relacionarse con la risa, el peligro, el drama, la superación, la competición, la exhibición...

Que antes un palo pudiera ser un revólver y ahora puedan conseguir la reproducción exacta de un AK-49; que antes la casita de muñecas reprodujese los roles y funciones del escenario del hogar como ahora lo hacen los Simms; que antes pusieran fotos de ciclistas en las chapas y ahora puedan sentarse en el McLaren Mp4-22, no significa que la función ficcional cambie: sólo tiene más y mejores medios.

Por otro lado, la ficción tiene zonas oscuras (como tienen los cuentos de hadas en los que los niños mueren o son devorados o abandonados por brujas, ogros y monstruos).

Los videojuegos son, muchas veces el lugar donde explorar lo obsceno (lo que está fuera de escena), lo prohibido... Casi siempre reconocen como temas prohibidos la violencia y el sexo, sólo que la violencia les parece más obscena cuando es extrema. Pero la zona oscura de los videojuegos que están vetados les atrae como cuando hace años los niños buscaban en el diccionario palabras tabú. 
Los niños y niñas comentan y conocen juegos prohibidos. Y señalan (porque reconocen) su violencia o su falta de idoneidad. Lo hacen entre risas, como cuando descubren lo prohibido en otros ámbitos: son "burradas" y casi por unanimidad reconocen que son propuestas que superan los límites que ellos deben respetar. Pero les fascina a unas y a otros lo que tienen de "mundo prohibido" o de exageración transgresora.

La capacidad de conceder identidad y de ofrecer un escenario /virtualmente real/ es lo que caracteriza un buen videojuego.

Todo cuanto signifique la capacidad de meterse en los mundos será bien valorado. Todo lo que borre la sensación de ficción será lo que califique el éxito del juego: gráficos, acción, variedad de personajes...

Quieren que la ficción sea lo más real posible.Y esto no sería posible si no supieran que hay diferencia: sólo se puede trascender lo real si se admite como tal.

Muchos juegos que nos dan miedo son para los jugadores problemas técnicos que se han de resolver.

Los juegos son “pantallas”. Que haya buenos o malos, amenazas sangrientas o mascotas que no se pueden educar y que destrozan la casa, batallas por la conquista de un imperio o concursos de karaoke son elementos del escenario ficcional.

De ahí que, como hábiles en resolver problemas, los niños y niñas más capaces son admirados en la misma medida que lo eran los que jugaban mejor a la peonza o a las canicas. A esto nos referimos con la estructura y función invariables del juego: no varían; lo que varían son las comodidades técnicas y la capacidad de reproducción de mundos que antes se construían con medios más limitados.

Así, los niños y niñas (con las salvedades de género debidas ya indicadas), admiran a los jugadores que poseen un conocimiento especializado de uno u otro juego. Y, aunque las niñas son menos sensibles a esta acumulación de conocimiento, participan igualmente de la curiosidad por los límites de los juegos: los técnicos y los morales. 
b) Los Padres.

En todos los estudios que hemos realizado, hemos observado que los niños y las niñas tienen herramientas de juicio, de criterio y de discernimiento entre el bien y el mal fundamentalmente vinculadas al acompañamiento de los adultos, tanto viendo la televisión como en el mundo de los videojuegos.

Desde el punto de vista del control de los contenidos, los padres, los adultos que han de estar con niños y niñas, tienen que ofrecer las lecturas adecuadas a lo que los niños leen. Deben abrir los campos de significados de los relatos en los que los niños se introducen y deben aportar criterios de valoración e, incluso de percepción.

En cuanto al soporte concreto, los videojuegos, curiosamente, se han convertido en un premio, en una cesión de los padres ante buenas notas o buen comportamiento cuando no están integrados en la oferta de ocio.

Y esto viene dado porque la desconfianza hacia lo audiovisual hace que los adultos se resistan a considerar las consolas o los juegos como parte de la actividad lúdica de los niños. Tantos años de discurso apocalíptico siguen haciendo de la consola y del ordenador (en su función de soporte lúdico) fuente de desconfianza. De hecho, es difícil recordar que hay videojuegos educativos... e incluso que hay videojuegos sin intención educativa primaria (Age of Empires, Caesar, Imperivm, Age of Mythologies, y tantos otros) que proporcionan una enorme cantidad de información histórica y estratégica.

Por otro lado, los niños y niñas saben que la consola y los juegos constituyen un equipamiento de hogar que señala status. Guste o no. Y como tal, los padres ceden también ante la presión que los pares ejercen sobre niños y niñas: “iah, no tienes la PS todavía?”, “mis padres ya me han comprado la DS", etc...

Sea como sea, los padres se enfrentan a la duda de la bondad o maldad de los videojuegos y a la presión de la adquisición de los soportes. Y, como reacción lógica, tienden a enfrentarse ante el problema del control del soporte (tiempos, espacios) y de los contenidos (violencia, adictividad, presentación de mundos y actividades marginales o incluso delictivas). 
Y ante el problema del control, parece que hay, según los niños y las niñas que han participado en el estudio, dos tipos principales de padres:

\section{a) Los que temen el videojuego y lo prohíben.}

Esto es fuente de tensiones en la familia: la demanda de los niños se hace resistencia. El videojuego y la consola se convierten en rehén, en moneda de cambio para que los niños y niñas obedezcan o realicen las actividades que se les exigen.

La prohibición, como procede de la desconfianza de la que hemos hablado, está relacionada con que este tipo de padres y madres no tenga un conocimiento preciso del conocimiento de las consolas y menos de los juegos; lo que hace que los videojuegos se conviertan también en un factor de separación entre el mundo de los niños y las niñas y el mundo de sus padres y madres.

b) Los que controlan el tiempo, el modo de uso y los videojuegos a los que tienen acceso los/as niños/as, pero admitiendo su uso como elemento de ocio.

En este caso, los padres conocen algo más de cerca el mundo de los juegos. De hecho, suelen ser padre y madres que jugaron a los videojuegos en su adolescencia o juventud, y los tienen incorporados a la oferta lúdica de sus hijos/as.

Suelen conocer (siquiera por encima) los tipos de juego, los tipos de consola y los contenidos. Desde luego, conocen que hay que limitar el tiempo por razones no sólo "de vigilancia”, sino también por razones físicas. Pero son abiertos a negociar los tiempos con las demás actividades de sus hijos e hijas.

En el caso más extremo, incluso este tipo de padres y madres pueden acceder a jugar con sus hijos y sus amigos. Como indicábamos arriba, esta actitud de compartir este espacio lúdico (como el resto de los padres hace con las actividades físicas, deportivas o culturales) les confiere más autoridad ante sus hijos e hijas. Incluso podríamos decir, en tono más humorístico, que padres y madres de este tipo dan un cierto "prestigio" a sus hijos e hijas frente a sus pares "el padre / la madre de Fulano mola. Además, en el FIFA World Player es un crack". 
En el fondo, el tipo de padre o madre /prohibicionista/ también hace que niños y niñas tiendan a jugar más en solitario y con un nivel mayor de adicción. Mientras que parece que, según los participantes, los padres y madres más /participativos/ tienden a favorecer el juego colectivo y el autocontrol de niños y niñas frente a los videojuegos.

El rasgo común entre todos los adultos es el tratar de ceñir el uso del videojuego a los fines de semana, o una vez terminados los deberes o las actividades extraescolares. Y también a limitar a una o dos horas el máximo de utilización de las consolas.

En el caso de las consolas portátiles, es experiencia común que son muy utilizadas en los viajes en automóvil o en tiempos de espera en espacios ajenos al hogar: consultas médicas, visitas a otros adultos, reuniones festivas en las que los niños están “apartados”, etc.

c) "La Revista dice...": Las Fuentes de Información.

Los niños en especial, algo menos las niñas, buscan información constantemente sobre los juegos. Las revistas, el boca a oído y la Internet son las fuentes principales. Recordemos que el saber es una marca de status ante los pares.

Recurren a todas esas fuentes para solventar "pantallas", como decíamos arriba: para resolver problemas o superar obstáculos especialmente difíciles.

Consultan revistas y páginas web de trucos, consejos y pistas, y se pasan la información en las conversaciones, sean cara a cara o sea en conversaciones virtuales a través del chat.

La búsqueda de información es, por tanto, para los niños (y en menor medida para las niñas) lugar de encuentro e interacción socializadora. El saber, el conocimiento especializado tiende a ser intensivo: unos son especialistas en este o aquel juego y otros lo son en este o aquel diferente. Y se convierte en marca de status frente a los pares, ante los que se presume de esta especialización.

En su aspecto extensivo, conocen, de primera mano o de oídas, un enorme corpus de juegos de todo tipo. Como ocurría con el yo-yo, las canicas, las peonzas o con las series de televisión, siguen modas y corrientes que se extienden a través de los canales mencionados. 
A veces, incluso, niños y niñas / se reparten/ la prueba de los juegos: unos compran un juego y otros otro y los evalúan, para más tarde recomendar o no su uso. Y si, como vimos, surge un juego especialmente violento o "exagerado", alguno de ellos o de ellas tendrá acceso y extenderá la información sobre él, probablemente entre risas nerviosas.

Este es un buen lugar para indicar un poco más concretamente la relación entre lo educativo y los videojuegos en esta corriente de información, modas e intercambio de información.

Muchos juegos son fuente de información en sí misma. Entre los juegos más jugados se encuentran juegos de resolución de problemas estratégicos, de reproducción de batallas y aun de corrientes históricas, mitológicas o políticas.

En muchas ocasiones, los manuales de juego o las pantallas de transición de estos juegos reúnen una ingente y muy divulgativa cantidad de información, alternativa (y muchas veces más divertida y fácil de asimilar) a la que niños y niñas reciben en las aulas.

Otros, como los simuladores sociales plantean conflictos y su resolución, estrategias personales y sociales en las que niños y niñas proyectan e intercambian habilidades y estrategias personales y sociales, y en los que, además, contrastan criterios éticos y de convivencia que reconocen como aplicaciones de su relación con los mundos adultos.

Como complemento a este aspecto, muchos videojuegos requieren también fuentes de información externas al soporte, exigiendo a niños y niñas un esfuerzo de documentación y de intercambio de información multi-soporte idéntico al que deben realizar en trabajos de elaboración en el aula o en otros contextos educativos.

Pero además, este último año, con el éxito de "Brain Training" y otros juegos similares, se ha demostrado que un videojuego educativo (estrictamente entendido como tal desde el punto de vista apocalíptico) puede ser líder de ventas.

Y esto viene dado, con toda probabilidad, por el hecho de que el diseño del juego se ha adaptado a las formas y límites del soporte-sea consola, consola portátil u ordenador-. Cuando un videojuego educativo fracasa, parece que es porque simplemente reproduce las formas y con- 
diciones de otros materiales educativos que los niños no asocian al videojuego, sino al aula o a los libros de este estilo ${ }^{1}$.

\section{d) En Resumen}

Para los niños el videojuego es un lugar de encuentro con pares, dentro y fuera del mundo virtual. Incluso a veces les gusta más mirar jugar a otros que jugar (sobre todo si no son hábiles con un juego).

Para las niñas, es un espacio más de relación. Sus juegos favoritos tienden a responder a este aspecto. Por ejemplo, las niñas asocian el chat con los videojuegos de ordenador.

Para todos, es una ocasión de "hacer algo" cuando en el mundo real no se tiene el medio o la oportunidad. Y también es el modo de realizar las fantasías con los medios tecnológicos que permiten hacerlas "más reales".

Es también, sobre todo para los niños, una ocasión de medir fuerzas, de competir y de demostrar conocimiento.

El hábitat tiende a ser importante para la función socializadora. A veces, en hábitats de aislamiento, no es el último refugio: es la única salida.

El papel de los padres y las madres (y de los educadores) como agentes socializadores, como lectores acompañantes de los contenidos de los videojuegos, es decisivo para niños y niñas. Un mayor y mejor conocimiento de este mundo lúdico es esencial para superar barreras entre el mundo adulto y el infantil y para tener mejores criterios a la hora de pactar y regular su uso.

\footnotetext{
1 De hecho, es la opinión de nuestro equipo, incluso los videojuegos con más contenido marginal pueden tener una función educativa: si los padres, madres y educadores acompañan a los niños y las niñas a "leer" estos juegos, tendrían que trabajar con ellos temas como la violencia, la marginalidad, el papel del género en la asignación de roles en los juegos,... contrastando así los presuntos contra-valores de los juegos más “preocupantes" con los valores que los adultos quieren que los niños y niñas interioricen. En este caso, la función educativa dependería más del trabajo de los adultos que de la simple prohibición del acceso a dichos contravalores.
} 


\section{Referencias bibliográficas}

Adese (2006) Hábitos y usos de los Videojuegos. Disponible en adese.es

Aguilera M y Mañas S. (2001) "Atravesando el espejo(mediaciones psicológicas y discursivas en las nuevas obras audiovisuales: el caso de los videojuegos)“, Comunicar, nº 17, pp.79-85.

Buckingham, D. (2000) After the Death of Childhood: Growing up in the age of electronic media. Cambridge,Polity Press.

Buckingham, D (2004) Educación en medios. Barcelona, Paidós.

Calvo,A. (2000) “Videojuegos y niños”. Cuadernos de Pedagogía, nº 291,pp59-62

Castells, P y Bofarull, I (2002) Enganchados a las pantallas. Barcelona, Planeta

Estalló, J.A. (1995) Los Videojuegos. Juicios y prejuicios. Barcelona, Planeta

Ferrer López Marina y San Román J.A. (2005)“Hábitos de uso de videojuegos en niños de 7 a 12 años en la Comunidad de Madrid”, Icono 14, revista de Comunicación y Nuevas Tecnologías, no 5 pp293-305

Garitaonandia, C et alt (1999)."Qué ven y cómo juegan los niños españoles" Zer. Vol 6.pp 67-97

Greenfield, P et alt.(1996) Interacting with video. Advances in applied developmental psychology. Stamford, Ablex Publishing corp.

Livingstone,S y Bovill,M (2001) Children and their Changing Media Environment. Lawrence Eribaum Associates

Manovich, L.(2005) El lenguaje de los nuevos medios de comunicación. La imagen en la era digital. Barcelona, Paidós.

Pablos Pons, J. Et alt (2003) "El juego y los Videojuegos. Algunas propuestas para su valoración.”. Primeras Noticias: comunicación y Pedagogía. No 191.pp 41-46

Tejeiro Salguero,R. Y Pelegrina del Río, M. (2003) Los videojuegos (qué son y cómo afectan) Barcelona, Ariel. 
